\title{
The Role of Carbohydrate Moiety on Thermostability of Cellulases from Humicola insolens $\mathrm{YH}-8$
}

\author{
Shinsaku HaYashida and Hazime Yoshioka \\ Department of Agricultural Chemistry, Kyushu University, Fukuoka, Japan \\ Received April 9, 1979
}

\begin{abstract}
Two types of cellulases, Avicelase and CMCase, from a thermophilic fungus Humicola insolens $\mathrm{YH}-8$ were glycoenzymes. Avicelase and CMCase contained $26.1 \%$ and $39.0 \%$, respectively, of carbohydrate residues which consisted of mannose and $\mathrm{N}$-acetylglucosamine. These enzymes, especially CMCase, showed remarkable thermal and $\mathrm{pH}$-stability. The partial removal of the carbohydrate residues, $60 \%$ with mixed-glycosidase and $90 \%$ with periodate oxidation and Smith degradation, resulted in a significant decrease in thermal and $\mathrm{pH}$-stability. The carbohydrate moiety was suggested to be a stabilizer of cellulases.
\end{abstract}

A thermophilic fungus, Humicola insolens YH-8 produced a remarkable amount of thermostable cellulases in culture in wheat bran medium at $50^{\circ} \mathrm{C}$ for 4 days. The culture extract hydrolyzed Avicel and newspaper without any physical or chemical pretreatment to the respective extents of $90 \%$ and $35 \%$ as glucose. Avicelase and CMCase* were purified from the culture extract and found to be homogeneous on polyacrylamide gel disc electrophoresis. Avicelase showed an optimum temperature at $50^{\circ} \mathrm{C}$, and indicated 70 percent relative activity in incubation at $60^{\circ} \mathrm{C}$ for $24 \mathrm{hr}$. Avicelase was stable at $\mathrm{pH} 3.5-9.5$ at $4^{\circ} \mathrm{C}$ for $24 \mathrm{hr}$. CMCase, which had the same optimum temperature as Avicelase, indicated 80 percent relative activity in incubation at $70^{\circ} \mathrm{C}$ for $24 \mathrm{hr}$ and 45 percent original activity after heating at $95^{\circ} \mathrm{C}$ for $5 \mathrm{~min}$. CMCase was stable at $\mathrm{pH} 3.0-11.0$ at $4^{\circ} \mathrm{C}$ for $24 \mathrm{hr}$. It was suggested that the high stability of these cellulases contributed to the high saccharifying extents of cellulosic substrates at $50^{\circ} \mathrm{C}$ by use of culture extract.

In this comminication, a proposal is advanced that carbohydrate residues covalently linked in the molecular structure of enzymes,

\footnotetext{
* Avicelase hydrolyzes more strongly water-insoluble substrate (native cellulose and Avicel) than watersoluble substrate (CMC). CMCase hydrolyzes more strongly water-soluble substrate than water-insoluble substrate.
}

function as a protective factor against heat and acidic or alkaline pHs. This suggestion is made from the result that carbohydrate-split enzymes are remarkably less stable than native cellulases.

\section{MATERIALS AND METHODS}

Preparation of cellulases. Humicola insolens $\mathrm{YH}-8$ was cultured in a 21-Erlenmeyer flask containing solid wheat bran medium to produce a remarkable amount of Avicelase and CMCase. Both enzyme preparations purified through consecutive column chromatography showed single protein bands on polyacrylamide gel disc electrophoresis. ${ }^{* *}$

Assay of enzymes. (a) Avicelase activity: The reaction mixture containing $100 \mathrm{mg}$ of Avicel (microcrystalline cellulose, Asahi Kasei Co., Tokyo). $5 \mathrm{ml}$ of $0.1 \mathrm{~m}$ acetate buffer of pH 5.5 and $5 \mathrm{ml}$ of enzyme solution, was shaken on a Monad-shaker at 90 strokes per minute at $50^{\circ} \mathrm{C}$ for appropriate periods. Reducing sugar formed was determined by the micro-Bertrand method $^{11}$ and phenol-sulfuric acid method. ${ }^{2}$ ) One unit of enzyme activity was defined as the amount of enzyme releasing $1 \mathrm{mg}$ of reducing sugar from the substrate per hour. (b) CMCase activity: Incubation was made in the same manner as that described for the Avicelase assay. One unit of CMCase activity was defined as the amount of enzyme releasing $1 \mathrm{mg}$ of reducing sugar from the substrate CMC (carboxylmethylcellulose, Wako Junyaku Kogyo Co., Osaka) per minute.

\footnotetext{
** A part of this work was presented at the Annual Meeting of the Agricultural Chemical Society of Japan at Nagoya, Japan, on April 3, 1978.
} 
Compositions of carbohydrate residues. The carbohydrate compositions were determined after hydrolyzing the purified enzyme preparations with $1 \mathrm{~N}$ hydrochloric acid at $100^{\circ} \mathrm{C}$ for $1 \mathrm{hr}$. The constituent sugars of the carbohydrate residues were identified with paper chromatography, as described in the next paragraph. Mannose and $\mathrm{N}$-acetylglucosamine contents were determined by the micro-Bertrand method ${ }^{1)}$ and Morgan-Elson reaction method, ${ }^{3)}$ respectively.

Preparations of cellulase- and protease-free glycosidase. Trace activities of cellulase and protease in mixed-glycosidase preparation (Turbo, Seikagaku Kogyo Co., Tokyo; $74 \mathrm{U} / \mathrm{mg}$ of $\alpha$-mannosidase, $133 \mathrm{U} / \mathrm{mg}$ of $N$-acetyl- $\beta$-glucosaminidase) were removed by DEAE-Sephadex A-50 column chromatography. The mixed-glycosidase preparation $(400 \mathrm{mg}$ ) was dissolved in $10 \mathrm{ml}$ of $0.05 \mathrm{M}$ phosphate buffer (pH 5.5), applied on a DEAE-Sephadex A-50 column $(1.5 \times 4.5 \mathrm{~cm})$ previously buffered with $0.05 \mathrm{M}$ phosphate buffer of $\mathrm{pH}$ 5.5 , and was eluted with a linear gradient from $0.05 \mathrm{M}$ to $1 \mathrm{M}$ phosphate buffer of $\mathrm{pH} 5.5$ at $4^{\circ} \mathrm{C}$. The flow rate was $10 \mathrm{ml}$ per hr, and the eluate collected in $5 \mathrm{ml}$ fractions. Glycosidase activity appeared in fraction No. 10-15. These fractions were combined, concentrated, completely desalted by filtration through a Sephadex G-50 column and lyophilized. The lyophilized samples had no cellulase or protease activity and was designated as Turbo-glycosidase.

Digestions of native cellulases with Turbo-glycosidase. Each purified Avicelase and CMCase sample $(500 \mathrm{mg})$ was dissolved in $10 \mathrm{ml}$ of $0.2 \mathrm{M}$ citrate-phosphate buffer of $\mathrm{pH} 4.0$, and incubated at $30^{\circ} \mathrm{C}$ for 2 days with $3 \mathrm{mg}$ of Turbo-glycosidase.

Mild Smith degradation. Each purified Avicelase and CMCase sample ( $500 \mathrm{mg}$ ) was dissolved in $100 \mathrm{ml}$ of $0.02 \mathrm{M}$ sodium metaperiodate in $0.05 \mathrm{M}$ sodium acetate buffer ( $\mathrm{pH} 5.0$ ) by standing for $24 \mathrm{hr}$ at $4^{\circ} \mathrm{C}$ in the dark. ${ }^{4)}$ After desalting by filtration through Sephadex G-15, the periodate-oxidized enzymes were adjusted to $\mathrm{pH} 9.5$ with sodium borohydride by standing for $16 \mathrm{hr}$ at $15^{\circ} \mathrm{C}$. The reaction mixture was desalted with filtration through Sephadex G-15, and adjusted to $\mathrm{pH}$ 1.0 with hydrochloric acid by standing for $8 \mathrm{hr}$ at $15^{\circ} \mathrm{C}$.

Determination of molecular weights. Molecular weights were determined with SDS-polyacrylamide gel electrophoresis. About $1 \mathrm{mg}$ of each cellulase preparation was incubated at $4^{\circ} \mathrm{C}$ for $10 \mathrm{hr}$ in $0.01 \mathrm{M}$ phosphate buffer $(\mathrm{pH} 7.2)$, containing $1 \%$ sodium dodecyl sulfate and $5 \% 2$-mercaptoethanol in a final volume of $1 \mathrm{ml}$. After addition of $\mathrm{BPB}$, solution containing $10 \% \mathrm{~g}$ of enzyme was layered on the top of the gel. Electrophoresis was carried out at $8 \mathrm{~mA}$ per tube $(0.5 \times 10 \mathrm{~cm})$ for $5 \mathrm{hr}$ with $0.1 \mathrm{M}$ phosphate buffer (pH 7.2), containing $0.1 \%$ SDS. The protein band was detected by staining with $0.5 \%$ amido black solution.

Paper chromatography. Paper chromatography was carried out at room temperature on Whatman No. 1 filter paper by ascending technique in a solvent of $n$-butanol-pyridine-water $(6: 4: 3)$. Sugars were detected by the dipping method with silver nitratesodium hydroxide reagent. ${ }^{\text {) }}$ ?

\section{RESULTS}

\section{Composition of carbohydrate residues in Avi- celase and CMCase}

As shown in Fig. 1, carbohydrate residues in Avicelase and CMCase were composed of mannose and $\mathrm{N}$-acetylglucosamine. Avicelase and CMCase contained 14.0 and 20.0 percent, respectively, of mannose, and 12.1 and 19.0 percent, respectively, of $N$-acetylglucosamine. The total content of carbohydrates in Avicelase and CMCase was 26.1 and 39.0 percent, respectively. The carbohydrate residues of both enzymes had abundant $N$-acetylglucosamine.

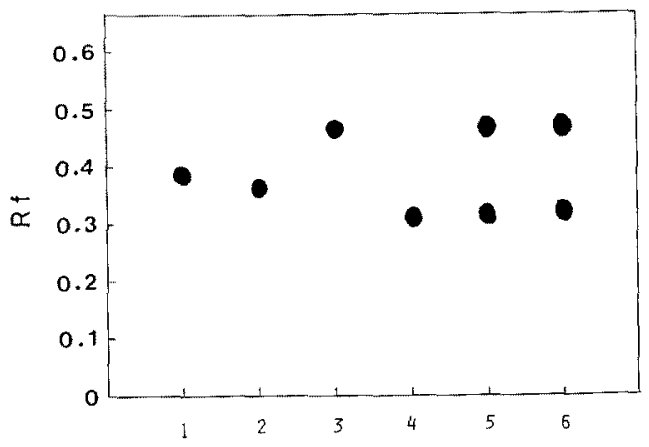

Fig. 1. Paper Chromatogram of Constituent Sugars of Avicelase and CMCase.

1, glucose marker; 2, galactose marker; 3 , mannose marker; 4, $\mathrm{N}$-acetylglucosamine-HCl marker; 5 , constituent sugars of Avicelase; 6, constituent sugars of CMCase.

Partial removals of carbohydrate moieties from native cellulases

Digested samples of both cellulases with Turbo-glycosidase were adjusted to $\mathrm{pH} 3.0$ with $1 \mathrm{~N}$ hydrochloric acid, followed by standing at $4^{\circ} \mathrm{C}$ overnight. Then centrifugation was performed to remove the precipitates formed. The supernatants were adjusted to $\mathrm{pH} 5.5$ with ammonia water, and applied to DEAE- 

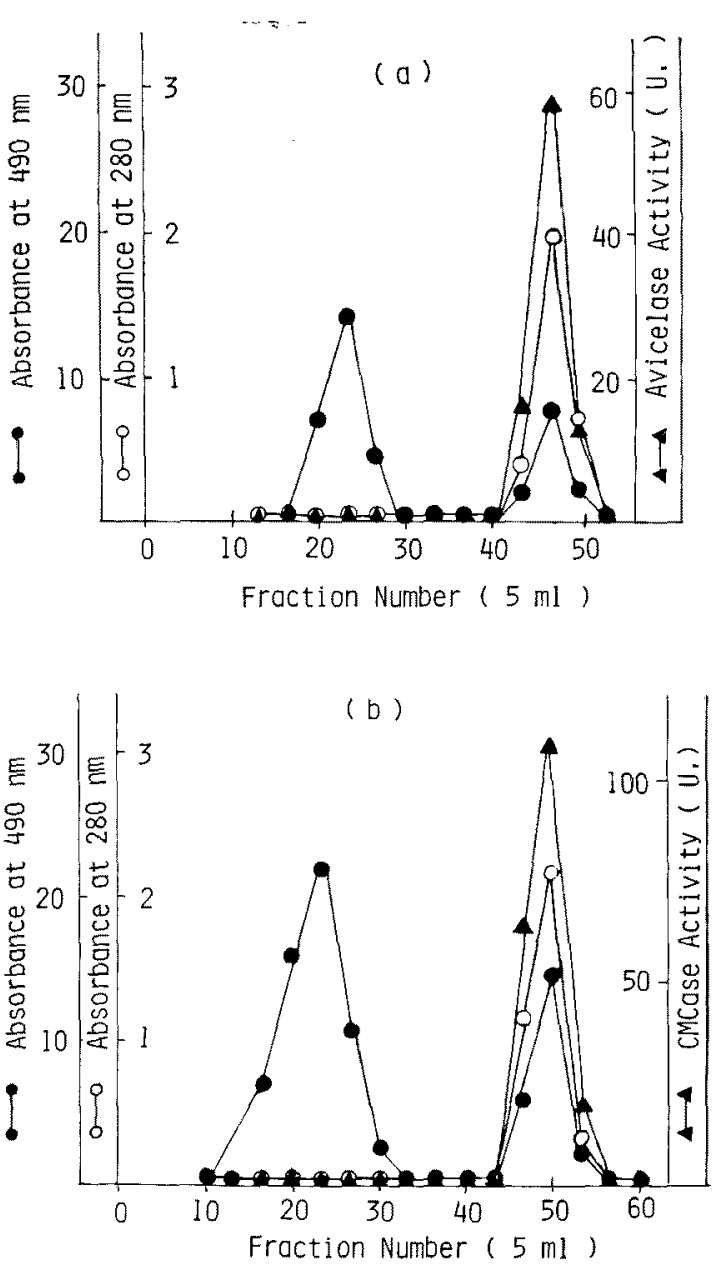

FIG. 2. DEAE-Sephadex A-50 Column Chromatographies of Digests of Avicelase and CMCase with Turbo-glycosidase.

(a) Avicelase digested with Turbo-glycosidase. (b) CMCase digested with Turbo-glycosidase. The experimental details are described in the text. $-\mathbf{A}$, Enzyme activity; $\bigcirc-0$, absorbance at $280 \mathrm{~nm} ; \bullet-\bullet$ absorbance at $490 \mathrm{~nm}$ with phenol-sulfuric acid reagent.

Sephadex A-50 columns $(2.3 \times 57 \mathrm{~cm})$ at $4^{\circ} \mathrm{C}$ by procedures described in Materials and Methods. Activities of Turbo-glycosidasedigested Avicelase and CMCase were found in fraction No. 42-49 and fraction No. 44-57, respectively (Fig. 2). The eluted positions were almost the same as those of native cellulases. The total content of carbohydrates in digested preparations of Avicelase and CMCase decreased to 9.3 percent and 13.6 percent, respectively, when sufficiently digested. These digested enzymes were designated as $65 \%$-carbohydrate-split enzymes.

The periodate-oxidized- and Smith-degradated-samples of both cellulases were adjusted to $\mathrm{pH} 5.5$ with hydrochloric acid, concentrated and then entirely desalted by filtration through a Sephadex G-15 column. The Smith-degradated-samples were further purified with DEAE-Sephadex A-50 column and then desalted by filtration through Sephadex $\mathrm{G}-50$. The total content of carbohydrates in degradated preparations of Avicelase and CMCase decreased to 2.5 and 4.0 percent, respectively. These digested enzymes were designated as $90 \%$-carbohydrate-split enzymes.

Molecular weight of native and carbohydratesplit cellulases

Though the molecular weights of native Avicelase and CMCase were 72,000 and 57,000, respectively, those of $65 \%$-carbohydrate-split cellulases became 60,000 and 43,000 , respectively. On the other hand, those of $90 \%$ carbohydrate-split cellulases became 55,000 and 37,000, respectively (Fig. 3).

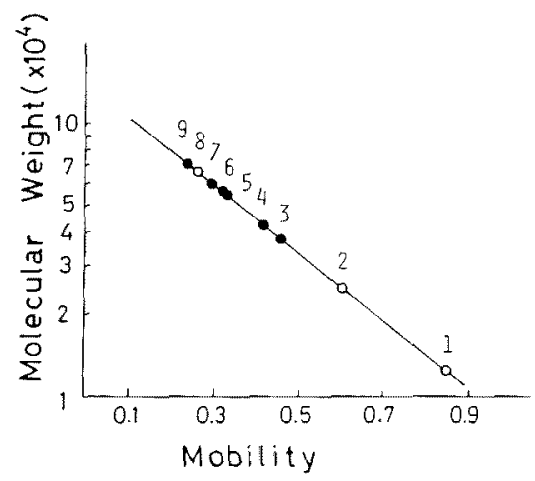

Frg. 3. Determination of Molecular Weights of Native and Carbohydrate-split Cellulases.

SDS-polyacrylamide gel electrophoresis was performed as described in the text. 1, cytochrome $\mathrm{C}$ (MW 12,400); 2, chymotrypsinogen A (MW 25,000); 3, 90\%-carbohydrate-split CMCase [MW 37,000]; 4, $65 \%$-carbohydrate-split CMCase [MW 43,000]; 5, 90\%-carbohydrate-split Avicelase [MW 55,000]; 6, native CMCase [MW 57,000]; 7, 65\%-carbohydratesplit Avicelase [MW 60,000]; 8 , bovine serum albumin (MW 67,000); 8, native Avicelase [MW 72,000]. 


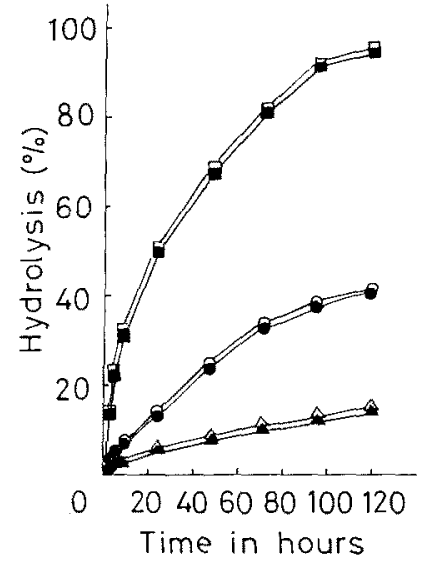

Fig. 4. Hydrolysis Curves of $65 \%$-Carbohydratesplit Cellulases on Avicel.

The reaction mixture consisting of $100 \mathrm{mg}$ of Avicel, $5 \mathrm{ml}$ of $0.1 \mathrm{M}$ acetate buffer $(\mathrm{pH} 5.5)$ and $5 \mathrm{ml}$ of enzyme solution $(100 \mu \mathrm{g} / \mathrm{ml})$ was incubated at $50^{\circ} \mathrm{C}$. The amount of reducing sugar formed was converted into the amount of cellobiose, and then the hydrolysis rate was calculated as percentage of the amount of cellobiose formed with enzyme per the amount of glucose formed with acid hydrolysis. $\bigcirc-O$, Native Avicelase; $\triangle-\Delta$, native CMCase; $\square--\square$, native Avicelase plus native CMCase; $-\bullet, 65 \%$-carbohydrate-split Avicelase; A-A, $65 \%$-carbohydratesplit CMCase; - - 65\%-carbohydrate-split Avicelase plus $65 \%$-carbohydrate-split CMCase.

Hydrolysis on Avicel with native and carbohydrate-split cellulases

As shown in Fig. 4, hydrolysis curves on Avicel with $65 \%$-carbohydrate-split cellulases were the same of those of native cellulases. The $65 \%$-carbohydrate-split Avicelase and CMCase hydrolyzed Avicel to 40 percent and 15 percent, respectively. Synergistic incubation of $65 \%$-carbohydrate-split Avicelase and CMCase hydrolyzed Avicel to 90 percent, the same as native enzymes. On the other hand, by successive chemical treatment by mild periodate oxidation and mild Smith degradation, Avicelase and CMCase showed somewhat weak activities, as seen in Fig. 5.

\section{Hydrolysis products of Avicel with native and carbohydrate-split cellulases}

Hydrolysis products of Avicel with carbohydrate-split cellulases incubated at $50^{\circ} \mathrm{C}$ for $24 \mathrm{hr}$ were the same of those of native cel-

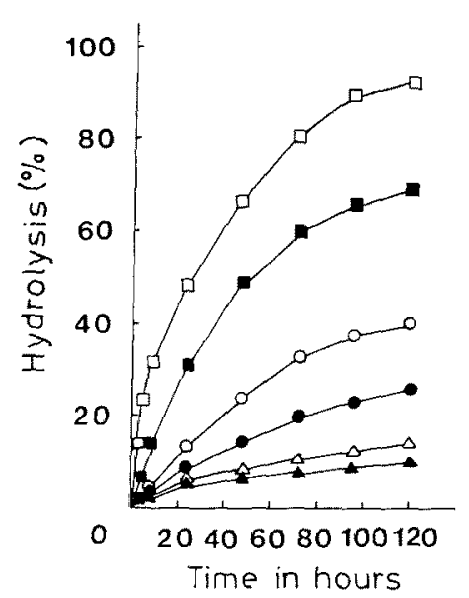

Frg. 5. Hydrolysis curves of $90 \%$-Carbohydrate-split Cellulases on Avicel.

The reaction mixture consisting of $100 \mathrm{mg}$ of Avicel, $5 \mathrm{ml}$ of $0.1 \mathrm{M}$ acetate buffer (pH 5.5) and $5 \mathrm{ml}$ of enzyme solution $(100 \mu \mathrm{g} / \mathrm{ml})$ was incubated at $50^{\circ} \mathrm{C}$. The amount of reducing sugar formed was converted into the amount of cellobiose, and then the hydrolysis rate was calculated as percentage of the amount of cellobiose formed with enzyme per the amount of glucose formed with acid hydrolysis. $0-0$, Native Avicelase; $\triangle-\triangle$, native $\mathrm{CMCase;} \square-\square$, native Avicelase plus native CMCase; $-\bullet, 90 \%$-carbohydrate-split Avicelase; A--, $90 \%$-carbohydrate-split CMCase; - - $90 \%$-carbohydrate-split Avicelase plus $90 \%$-carbohydrate-split CMCase.

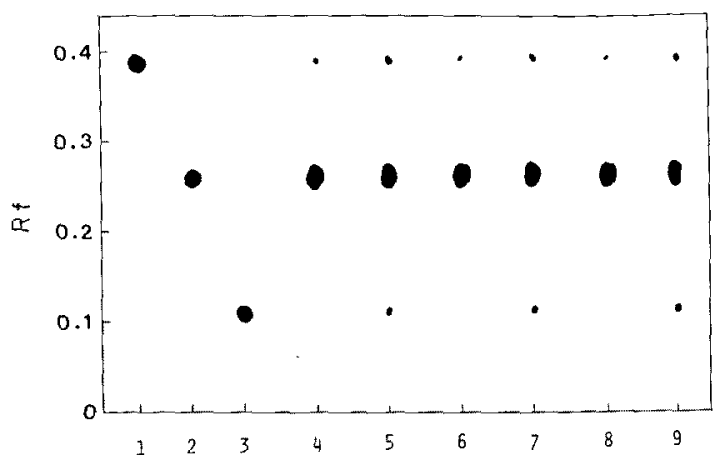

FIG. 6. Paper Chromatogram of Avicel Hydrolysates with Native and Carbohydrate-split Cellulases Incubated at $50^{\circ} \mathrm{C}$ for $24 \mathrm{hr}$.

1 , glucose marker; 2 , cellobiose marker; 3 , cellotriose marker; 4, hydrolysates with native Avicelase; 5, hydrolysates with native CMCase; 6 , hydrolysates with $65 \%$-carbohydrate-split Avicelase; 7 , hydrolysates with $65 \%$-carbohydrate-split CMCase; 8 , hydrolysates with $90 \%$-carbohydrate-split Avicelase; 9 , hydrolysates with $90 \%$-carbohydrate-split CMCase. 
lulases, as shown in Fig. 6. The products of Avicel with carbohydrate-split Avicelases were cellobiose and glucose. The products of Avicel with carbohydrate-split CMCases were cellobiose, cellotriose and glucose. With the synergistic action of carbohydrate-split preparations of Avicelase and CMCase, Avicel was hydrolyzed as cellobiose and glucose.

\section{Activities of native and carbohydrate-split cel- lulases}

The specific activities of $65 \%$-carbohydratesplit cellulases were almost the same of those of native cellulases, whereas $90 \%$-carbohydrate-split Avicelase and CMCase were found to retain 70 percent and 90 percent, respectively, of original activity, as shown in Table I.

Table I. Specific Activity of Native and Carbohydrate-SPlit Cellulases

\begin{tabular}{lccc}
\hline & Native & $\begin{array}{l}65 \% \text { Carbo- } \\
\text { hydrate-split }\end{array}$ & $\begin{array}{c}90 \% \text { Carbo- } \\
\text { hydrate-split }\end{array}$ \\
\hline Avicelase & 17.3 & 17.4 & 11.9 \\
\hline CMCase & 39.2 & 39.4 & 34.5 \\
\hline
\end{tabular}

Specific activity was expressed as units per $\mathrm{mg}$ of protein.

\section{Adsorbabilities of native and carbohydrate-split} Avicelases onto Avicel

As shown in Fig. 7, 65\%-carbohydrate-split Avicelase was completely adsorbed onto Avicel as native enzyme, whereas $90 \%$-carbohydratesplit Avicelase also retained 73 percent of

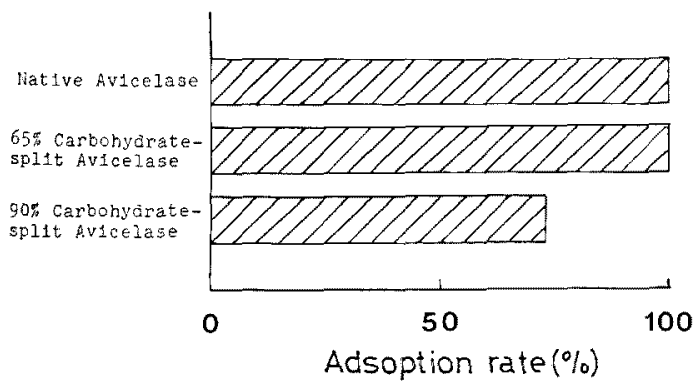

FIG. 7. Adsorption of Native and Carbohydratesplit Cellulases onto Avicel.

Each enzyme $(10 \mu \mathrm{g} / \mathrm{ml})$ in $5 \mathrm{ml}$ of $0.1 \mathrm{M}$ acetate buffer, $\mathrm{pH} 5.5$, was applied to $1 \mathrm{~g}$ of Avicel, followed by standing at $4^{\circ} \mathrm{C}$ for $10 \mathrm{~min}$. After centrifugation, Avicelase activity in the supernatant fluid was assayed, and the adsorption rate was calculated. adsorbability onto Avicel.

Thermal stability of native and carbohydratesplit cellulases

The thermal stabilities of native cellulases, $65 \%$-carbohydrate-split cellulases and $90 \%$ carbohydrate-split cellulases were compared in

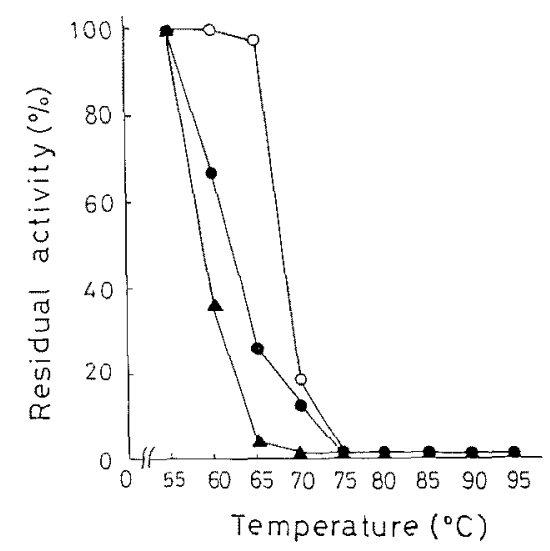

Fig. 8. Thermal Stability of Native and Carbohydrate-split Avicelases.

Avicelase activity was measured after allowing the reaction mixture to stand at $\mathrm{pH} 5.5$ for $5 \mathrm{~min}$ at varjous temperatures. The residual activity was expressed as percent of untreated control. $\bigcirc-0$, Native Avicelase; -, $65 \%$-carbohydrate-split Avicelase; $\boldsymbol{\Delta} \boldsymbol{- \Lambda}, 90 \%$-carbohydrate-split Avicelase.

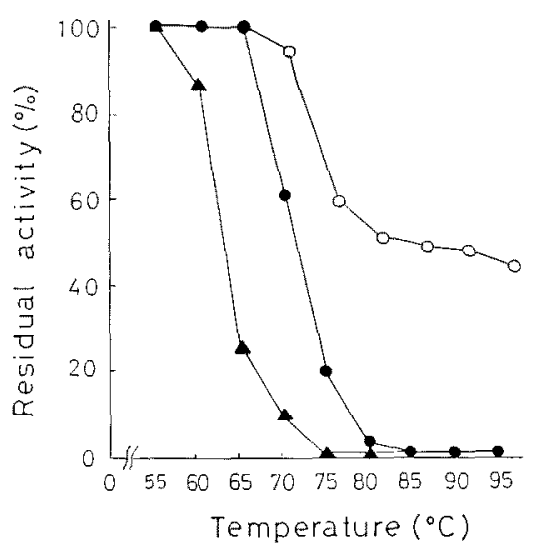

FrG. 9. Thermal Stability of Native and Carbohydrate-split CMCases.

CMCase activity was measured after allowing the reaction mixture to stand at $\mathrm{pH} S .5$ for $5 \mathrm{~min}$ at various temperatures. The residual activity was expressed as percent of untreated control. $\mathrm{O}-\mathrm{O}$, Native CMCase; - $-65 \%$-carbohydrate-split

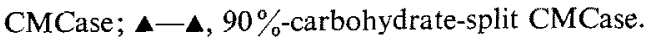


Fig. 8 and Fig. 9, respectively. Native Avicelase was stable after heating at $65^{\circ} \mathrm{C}$ for $5 \mathrm{~min}$, and native $\mathrm{CMCase}$ retained 45 percent of original activity after heating at $95^{\circ} \mathrm{C}$ for $5 \mathrm{~min}$. When 90 percent of the carbohydrate residues of each enzyme was liberated, Avicelase was

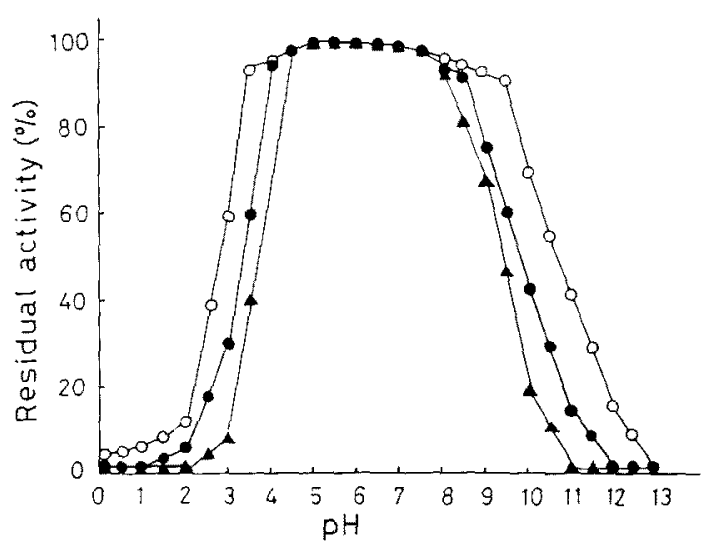

FIG. 10. pH-Stability of Native and Carbohydratesplit Avicelases.

Avicelase activity was measured after allowing the reaction mixture to stand at $4^{\circ} \mathrm{C}$ for $24 \mathrm{hr}$ at various pHs. The residual activity at optimal condition was expressed as percent of untreated control. $0-0$, Native Avicelase; - $65 \%$-carbohydrate-split Avicelase; $\mathbf{\Delta}, \mathbf{4}$, 90-carbohydrate-split Avicelase.

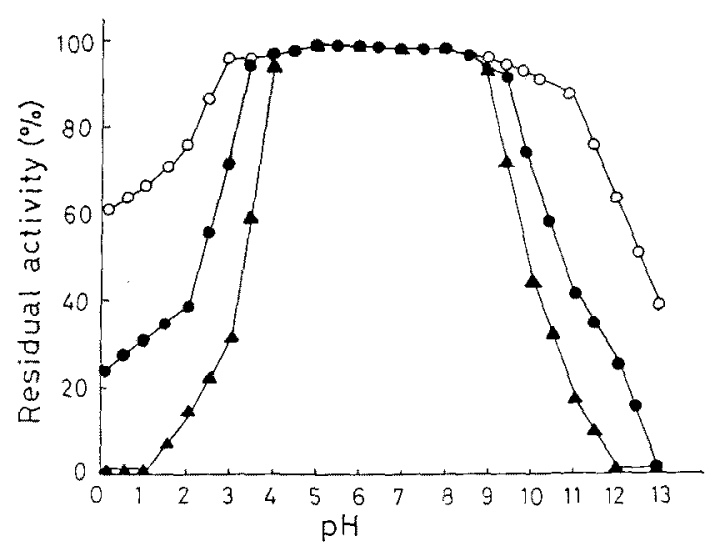

FIG. 11. pH-Stability of Native and Carbohydratesplit CMCases.

CMCase activity was measured after allowing the reaction mixture to stand at $4^{\circ} \mathrm{C}$ for $24 \mathrm{hr}$ at various pHs. The residual activity at optimal condition was expressed as percent of untreated control. $\mathrm{O}-\mathrm{O}$, Native CMCase; - $65 \%$-carbohydrate-split CMCase; $\Delta-\Delta, 90 \%$-carbohydrate-split CMCase. inactivated after heating at $65^{\circ} \mathrm{C}$ for $5 \mathrm{~min}$, and $\mathrm{CMCase}$ was inactivated after heating at $75^{\circ} \mathrm{C}$ for $5 \mathrm{~min}$.

\section{pH-Stability of native and carbohydrate-split cellulases}

Native Avicelase and CMCase were stable at $\mathrm{pH}$ 3.5-9.5 and $\mathrm{pH}$ 3.0-11.0, respectively, at $4^{\circ} \mathrm{C}$ for $24 \mathrm{hr}$. As shown in Fig. 10 and Fig. 11, however, the stability of $65 \%$-carbohydrate-split Avicelase and CMCase was lowered to $\mathrm{pH} 4.0-8.5$ and $\mathrm{pH} 3.5-9.5$, respectively, and the stability of $90 \%$-carbohydrate-split Avicelase and CMCase was lowered to $\mathrm{pH} 4.5-8.0$ and $\mathrm{pH} 4.0-9.0$, respectively.

\section{DISCUSSION}

This investigation found that the thermal and $\mathrm{pH}$-stabilities of cellulases from Humicola insolens $\mathrm{YH}-8$ had a correlationship with their carbohydrate moieties.

In order to check the possible influence of carbohydrate moieties on thermal and $\mathrm{pH}$ stabilities, the carbohydrate residues of purified enzymes were partially removed with mixedglycosidase or mild Smith degradation. By mixed-glycosidase digestion and Smith degradation, 65 percent and 90 percent, respectively, of carbohydrate moieties were liberated from cellulase. The comparison of the properties of native cellulases with the properties of carbohydrate-split cellulases have shown that the removal of carbohydrates from cellulase does not exert a gross influence on specific activity, hydrolysis curves on Avicel, hydrolysis products of Avicel and adsorbability onto Avicel. Quite clearly, however, partial removal of carbohydrate moieties from both cellulases resulted in a significant decrease in thermal and $\mathrm{pH}$-stability.

Some reports ${ }^{(, 7)}$ have indicated that removal of carbohydrate residues from enzyme with periodate oxidation and Smith degradation has exerted a gross influence not only on the stability of the enzyme but also on enzyme activity. For example, shown in yeast invertase, invertase activity towards sucrose and 
raffinose dropped to about $38 \%$ and $35 \%$, respectively, of original activity, during periodate oxidation. The thermostable cellulases from Humicola insolens YH-8, however, have been found to retain considerable catalytic activity even when 90 percent of carbohydrates was removed from protein with our technique of mild Smith degradation.

It is suggested that the characteristically high stability of native Avicelase and CMCase is attributed to an abundance of carbohydrate moieties which characteristically have high content of $\mathrm{N}$-acetylglucosamine. The relationship between high stability and the chemical structure of the carbohydrate moieties of these cellulases will be reported in next papers.

\section{REFERENCES}

1) G. Bertrand, Bull. Soc. Chim. Paris, 35, 1285 (1906).

2) M. Dubois, K. A. Gilles, J. K. Hamilton, P. A. Rebers and F. Smith, Anal. Chem., 28, 350 (1956).

3) W. T. J. Morgan and L. A. Elson, Biochem. J., 28, 988 (1934).

4) H. Yamaguchi, T. Ikenaka and Y. Matsushima, J. Biochem., 65, 793 (1969).

5) W. E. Trevelyan, D. P. Procter and J. S. Harrison, Nature, 166, 444 (1950).

6) J. H. Pazur, H. R. Knull and D. L. Simpson, Biochem. Biophys. Res. Commun., 40, 110 (1970).

7) Y. Tashiro and J. R. Trevithick, Can. J. Biochem., 55, 249 (1977). 